Amir Ali Mahboobipour and Shadi Baniasadi*

\title{
Clinically important drug-drug interactions in patients admitted to hospital with COVID-19: drug pairs, risk factors, and management
}

https://doi.org/10.1515/dmdi-2020-0145

Received August 18, 2020; accepted October 27, 2020; published online December 23, 2020

\section{Abstract}

Objectives: Coronavirus disease 2019 (COVID-19) is an emerging viral infection without any approved treatment. Investigational therapies for COVID-19 may cause clinically important drug-drug interactions (DDIs). We aimed to study potential DDIs (pDDIs) and their risk factors in COVID-19 patients admitted to the hospital.

Methods: We conducted a cross-sectional study in a tertiary respiratory hospital dedicated to COVID-19 patients. The Lexi-Interact database was used to investigate clinically important pDDIs. The database output including interacting drug pairs, risk rating, reliability rating, mechanism, and management was evaluated. Associations between the occurrence of pDDIs and probable risk factors were assessed by logistic regression analysis.

Results: Medical charts of 227 patients were reviewed. About $38 \%$ of the patients had at least one clinically important pDDI. More than half of the interactions were between protease inhibitors (lopinavir/ritonavir) and regularly prescribed medications for the management of comorbidities or COVID-19 symptoms (e.g., atorvastatin, alprazolam, salmeterol, and tamsulosin). Ischemic heart disease, chronic respiratory diseases, and ICU admission were significantly associated with the occurrence of pDDIs.

Conclusions: We recommend considering the risk factors for the emergence of clinically important DDIs in the pharmacotherapy of COVID-19 patients. Using an alternative medication or dose adjustments may be required in high-risk patients.

Keywords: COVID-19; drug-drug interaction; risk factor.

*Corresponding author: Shadi Baniasadi, PharmD, PhD, Tracheal Diseases Research Center, National Research Institute of Tuberculosis and Lung Diseases, Masih Daneshvari Hospital, Tehran, Iran, Tel./Fax: +98 21 26105387, E-mail: sbaniasadi@yahoo.com. https://orcid.org/ 0000-0002-3918-0104

Amir Ali Mahboobipour, School of Medicine, Tehran University of Medical Sciences, Tehran, Iran, E-mail: amahboobipour@yahoo.com

\section{Introduction}

The Coronavirus disease 2019 (COVID-19) is an infectious disease caused by severe acute respiratory syndrome coronavirus 2 (SARS-CoV-2). The World Health Organization (WHO) characterized it as a pandemic on 11 March 2020 [1]. Although the disease is not severe in most patients [2], it may progress to serious illness and hospitalization particularly in the elderly and those with underlying diseases [3].

There is not yet any approved drug or vaccine to treat COVID-19 and treatment is principally supportive [4]. However, medications approved for other viral diseases such as Ebola, HIV, and influenza are being experimentally applied against COVID-19 [5, 6]. American Society of Health-System Pharmacists (ASHP) has provided a list of COVID-19-related treatments (including antiviral agents, supportive agents, and other medications) and the evidence for them [7]. It is estimated that as many as 800 clinical trials are being planned or performed worldwide to investigate these treatments [5].

Meanwhile, the scientists and clinicians are evaluating different therapies to discover the most effective treatments for COVID-19, they should also consider developing data on adverse effects and potential drug-drug interactions (pDDIs) [8]. The pDDIs may occur between the main treatments and the medications for the management of the wide spectrum of clinical symptoms of COVID-19 and/or underlying medical comorbidities [9]. Recently, Lemaitre et al. described pDDIs between experimental COVID-19 therapies and other medications [10]. However, data on pDDIs in COVID-19 patients in real practice are not available. We designed the current study to investigate pDDIs and their risk factors in COVID-19 patients admitted to the hospital.

\section{Materials and Methods}

\section{Study design, setting, and participants}

This retrospective cross-sectional study was carried out in Masih Daneshvari hospital, a respiratory center dedicated to COVID-19 patients in Tehran, Iran. COVID-19 patients admitted to the hospital from 
12-26 March 2020 were included in the study. COVID-19 cases were confirmed by polymerase chain reaction (PCR) test according to the WHO case definition [1]. The Ethical Review Board of the National Research Institute of Tuberculosis and Lung Diseases approved the study protocol.

\section{Data collection}

The data were collected from the medical records of the patients under the supervision of a clinical pharmacologist. Age, sex, body mass index (BMI), past medical history, length of hospital stay, intensive care unit (ICU) admission (directly or after admission to the ward), patients' outcome (discharge or death), and the medications prescribed $24 \mathrm{~h}$ after admission (within $24 \mathrm{~h}$ of admission, the prescriptions are usually subject to modification) were gathered. The medications prescribed before admission were included if they were continued $24 \mathrm{~h}$ after admission. Patients who stayed in the hospital for less than $24 \mathrm{~h}$ were excluded.

The Lexi-Interact database (Lexicomp ${ }^{\circledR}$, Wolters Kluwer, Hudson, OH, USA, available on UpToDate, 2020) was applied to assess pDDIs. The Lexi-Interact database is an interaction analysis tool, which can identify possible interactions between drug pairs in a patient. The result of the analysis includes risk and reliability ratings scales. The output of the database also recommends patient management and discusses the probable mechanism of the interaction $[11,12]$.

Risk rating reflects both the level of urgency and the nature of actions necessary to respond to an interaction [12]. Based on the risk rating, the interactions are categorized into five categories including $\mathrm{A}$ (no known interaction), B (no action needed), C (monitor therapy), D (modify regimen), and X (avoid combination) [11]. Reliability rating indicates the quantity and nature of documentation for an interaction and is scaled as excellent (E), good (G), or fair (F) [12].

\section{Data analysis}

Data were entered into Statistical Package for Social Science version 22.0 (SPSS 22.0) for Windows (SPSS, Chicago, IL, USA). Both descriptive and analytical analyses were performed on the data. Due to the low clinical importance of interactions with a risk rating of A, B, and $\mathrm{C}$, only interactions with $\mathrm{D}$ and $\mathrm{X}$ scales were considered for further analysis. The interactions with excellent, good, and fair levels of evidence were included. Although available evidence for fair interactions is poor, they should be suspected because of pharmacologic considerations or good evidence for an interaction of pharmacologically similar drug [13].

Descriptive analyses of the variables were expressed as mean, standard deviation [SD], median, interquartile range [IQR], and percentage as appropriate. The association between the occurrence of pDDIs and probable risk factors was assessed using logistic regression analysis. The dependent variable was defined as exposure to at least one D or X interaction. Patient's sex, age, common comorbidities (hypertension, obesity, diabetes, ischemic heart disease [IHD], chronic respiratory diseases [CRDs], neoplasms), and ICU admission were taken as the covariates. At first, univariate logistic regression analysis was carried out. Variables with a significant univariate p-value $(<0.05)$ were further assessed by multivariate analysis.

\section{Results}

\section{Demographics and clinical presentation}

Two hundred and sixty-two medical charts of patients with confirmed COVID-19 were evaluated. Thirty-five patients were excluded due to the length of hospital stay (less than $24 \mathrm{~h}$ ). Table 1 shows the demographic and clinical characteristics of the patients. Of the total study population, $60.8 \%$ were male. A median number of eight medications (IQR, 6-9) were administered for the patients. At least one comorbidity was detected in $67.8 \%$ of

Table 1: Demographic and clinical characteristics of the patients.

\begin{tabular}{|c|c|}
\hline Study population & n (\%) \\
\hline Number of patients & 227 \\
\hline Age, mean (SD), years & $57.7( \pm 15.0)$ \\
\hline Hospital stay, median (IQR), days & $5(4-8)$ \\
\hline Number of drugs, median (IQR) & $8(6-9)$ \\
\hline \multicolumn{2}{|l|}{ Sex } \\
\hline Male & $138(60.8 \%)$ \\
\hline Female & $89(39.2 \%)$ \\
\hline $\begin{array}{l}\text { ICU admission (directly or after admission to the } \\
\text { ward) }\end{array}$ & $40(17.6 \%)$ \\
\hline Death & $21(9.3 \%)$ \\
\hline \multicolumn{2}{|l|}{ Chief complaint } \\
\hline Fever & $35(15.4 \%)$ \\
\hline Cough & $45(19.8 \%)$ \\
\hline Dyspnea & $128(56.4 \%)$ \\
\hline Fatigue or myalgia & 19 (8.4\%) \\
\hline Any comorbidity $^{a}$ & $154(67.8 \%)$ \\
\hline Hypertension & $69(30.4 \%)$ \\
\hline Obesity (BMI $\geq 30)$ & $63(27.8 \%)$ \\
\hline Diabetes & $54(23.8 \%)$ \\
\hline Ischemic heart disease & $31(13.7 \%)$ \\
\hline Chronic respiratory diseases (Asthma/COPD) & $15(6.6 \%)$ \\
\hline Neoplasms & $10(4.4 \%)$ \\
\hline Diseases of the genitourinary system & $9(4.0 \%)$ \\
\hline Nervous system disease & $8(3.5 \%)$ \\
\hline $\begin{array}{l}\text { Other endocrine, nutritional and metabolic } \\
\text { diseases }^{\text {b }}\end{array}$ & $7(3.1 \%)$ \\
\hline Other diseases of the circulatory system ${ }^{c}$ & $7(3.1 \%)$ \\
\hline $\begin{array}{l}\text { Diseases of the musculoskeletal system and } \\
\text { connective tissue }\end{array}$ & $5(2.2 \%)$ \\
\hline $\begin{array}{l}\text { Diseases of the blood and blood-forming organs } \\
\text { and certain disorders involving the immune } \\
\text { mechanism }\end{array}$ & $4(1.8 \%)$ \\
\hline Mental and behavioral disorders & $3(1.3 \%)$ \\
\hline Diseases of the digestive system & $2(0.9 \%)$ \\
\hline Certain infectious and parasitic diseases & $1(0.4 \%)$ \\
\hline
\end{tabular}

ancommon comorbidities were classified according to the International Classification of Diseases by WHO (ICD-10). ${ }^{\mathrm{b}} \mathrm{Not}$ including diabetes and obesity. ${ }^{\mathrm{C}}$ Not including hypertension and ischemic heart disease. 


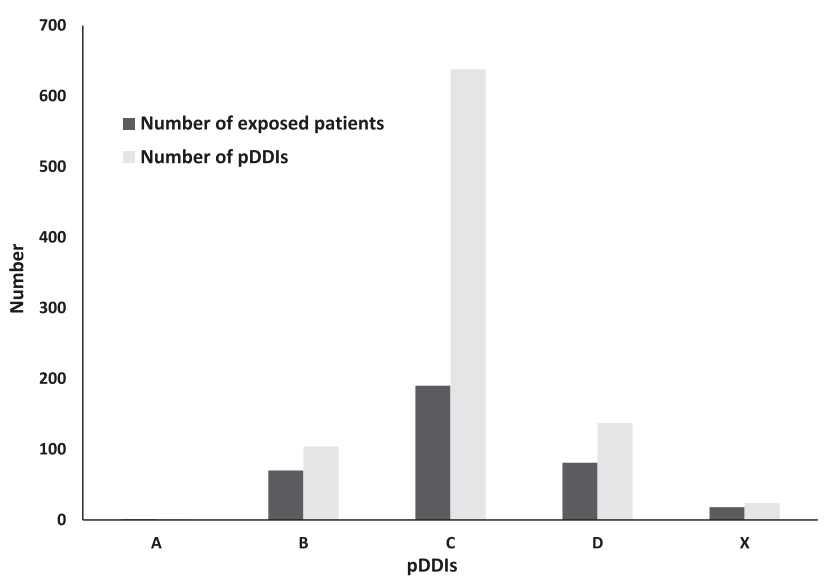

Figure 1: Number of potential drug-drug interactions (pDDIs) in different risk rating categories $(\mathrm{A}, \mathrm{B}, \mathrm{C}, \mathrm{D}, \mathrm{X})$ and the number of patients exposed to each category.

the patients. Hypertension (30.4\%) was the most common comorbidity followed by obesity $(27.8 \%)$ and diabetes $(23.8 \%)$.

\section{Drug-drug interactions}

Figure 1 shows the number of pDDIs in each category and exposed patients. Interactions with the risk rating of $\mathrm{D}$ and $\mathrm{X}$ were $17.8 \%$ of total pDDIs (161 of 904 ). About $38 \%$ of the patients (86 of 227) were exposed to at least one D or X interaction.

Drug combinations, frequency, reliability rating, mechanism, and applicable recommendations for $\mathrm{D}$ and $\mathrm{X}$ interactions are shown in Tables 2 and 3, respectively. Of the total pDDIs with the risk rating of $\mathrm{D}$ and $\mathrm{X}, 23.6 \%$ were unique drug pairs (the interaction occurred one time) (Supplementary Material, Appendix 1). The most frequent interactions were between lopinavir/ritonavir and commonly used medications metabolized by cytochrome P450 3A4 (CYP3A4) such as atorvastatin and alprazolam in the $\mathrm{D}$ category and salmeterol/fluticasone and tamsulosin in the $\mathrm{X}$ category. The reliability rating of $18 \%$ of $\mathrm{D}$ and $\mathrm{X}$ interactions was good and excellent.

\section{Risk factors}

In univariate logistic regression analysis, the occurrence of $\mathrm{D}$ and $\mathrm{X}$ pDDIs was significantly associated with age, four comorbidities (hypertension, diabetes, IHD, CRDs), and ICU admission as an indicator of COVID-19 severity. Multivariate analysis showed the independent predictors of occurrence of pDDIs are IHD (OR: 4.6, [95\% CI: 1.7-12.7], $\mathrm{p}=0.003$ ), CRDs (OR:3.5, [95\% CI: 1.0-12.2], $\mathrm{p}=0.045$ ), and ICU admission (OR: 3.3, [95\% CI: 1.4-6.7], p=0.004) (table 4).

\section{Discussion}

Infection control measures and supportive cares are currently the main clinical management for COVID-19. However, some medications are being used based on the results of laboratory, animal, and clinical studies [7]. The current study is the first to retrospectively identify risk rating, frequency, reliability rating, mechanism, and clinical management of pDDIs in hospitalized patients with COVID-19. We found that 37.9\% of COVID-19 patients were exposed to at least one D or X pDDI during the hospital stay. More than half of pDDIs occurred between lopinavir/ ritonavir (branded as Kaletra) and a medication metabolized by CYP3A4 (such as atorvastatin, alprazolam, salmeterol, and tamsulosin). Additive interactions between antiplatelets/nonsteroidal anti-inflammatory drugs (NSAIDs) and anticoagulants were the second common pDDI in COVID-19 patients.

Lopinavir, a protease inhibitor, is widely used for the treatment of HIV. It is combined with ritonavir, another protease inhibitor, which inhibits the CYP3A4 enzyme and increases the half-life of lopinavir [14]. Lopinavir/ritonavir has activity against severe acute respiratory syndrome coronavirus (SARS-CoV) and Middle East respiratory syndrome coronavirus (MERS-CoV) both in vitro and in animal models $[15,16]$. An open-label, randomized, phase 2 trial revealed the efficacy and safety of lopinavir/ritonavir combined with interferon beta- $1 \mathrm{~b}$ and ribavirin in the treatment of hospitalized patients with COVID-19 [17]. However, according to ASHP evidence assessment, lopinavir/ritonavir efficacy for the treatment of COVID-19 has not been established [7]. Despite low evidence of efficacy, it is prescribed in certain low- and middle-income countries due to its cost and accessibility. Both lopinavir and ritonavir have important DDIs due to inhibition of CYP3A4 [18].

Our results show that HMG-CoA reductase inhibitors (atorvastatin, rosuvastatin) are the most frequent interacting medications with lopinavir/ritonavir in our patients. Some studies revealed coadministration of different protease inhibitors with atorvastatin increased the area under the concentration-time curve (AUC) of atorvastatin from 1.7- to 9.4-folds (depending on the type of protease inhibitor) $[19,20]$. Reducing atorvastatin dose to $20 \mathrm{mg} /$ day and monitoring for signs and symptoms of its toxicity [myalgia, rhabdomyolysis, and liver function test (LFT) abnormalities] should be taken into account when a protease 
Table 2: Drug combinations, frequency, reliability rating, mechanism, and recommendations for $D$ interactions (modify regimen) based on Lexi-Interact database [11, 12].

\begin{tabular}{|c|c|c|c|c|}
\hline Drug combination & $\mathbf{n}$ & $\operatorname{Re}^{a}$ & Mechanism/effect & Recommendations \\
\hline $\begin{array}{l}\text { Lopinavir/ } \\
\text { Ritonavir + Atorvastatin }\end{array}$ & 32 & $\mathrm{~F}$ & $\begin{array}{l}\text { CYP3A4 inhibitors }{ }^{\mathrm{b}} \text { may increase the serum } \\
\text { concentration of atorvastatin }\end{array}$ & $\begin{array}{l}\text { Start with the lowest possible atorvastatin dose, } \\
\text { monitor for signs and symptoms of toxicity }\end{array}$ \\
\hline Aspirin + Enoxaparin & 13 & $\mathrm{~F}$ & $\begin{array}{l}\text { Antiplatelet agents may enhance the anti- } \\
\text { coagulant effect of Enoxaparin }\end{array}$ & Monitor closely for signs and symptoms of bleeding \\
\hline Lopinavir/Ritonavir + Alprazolam & 10 & G & $\begin{array}{l}\text { CYP3A4 inhibitors may increase the serum } \\
\text { concentration of alprazolam }\end{array}$ & Consider using an alternative \\
\hline Clopidogrel + Enoxaparin & 5 & $\mathrm{~F}$ & $\begin{array}{l}\text { Antiplatelet agents may enhance the anti- } \\
\text { coagulant effect of enoxaparin }\end{array}$ & Monitor closely for signs and symptoms of bleeding \\
\hline $\begin{array}{l}\text { Lopinavir/ } \\
\text { Ritonavir + Dexamethasone }\end{array}$ & 5 & $\mathrm{~F}$ & $\begin{array}{l}\text { CYP3A4 inhibitors may increase the serum } \\
\text { concentration of dexamethasone }\end{array}$ & $\begin{array}{l}\text { Monitor for increased adverse effects of dexameth- } \\
\text { asone, consider dose reduction }\end{array}$ \\
\hline $\begin{array}{l}\text { Lopinavir/ } \\
\text { Ritonavir + Prednisolone }\end{array}$ & 5 & $\mathrm{~F}$ & $\begin{array}{l}\text { CYP3A4 Inhibitors may increase the serum } \\
\text { concentration of prednisolone }\end{array}$ & $\begin{array}{l}\text { Monitor for increased adverse effects of predniso- } \\
\text { lone, consider dose reduction }\end{array}$ \\
\hline $\begin{array}{l}\text { Lopinavir/ } \\
\text { Ritonavir + Rosuvastatin }\end{array}$ & 5 & $\mathrm{~F}$ & $\begin{array}{l}\text { CYP3A4 Inhibitors may increase the serum } \\
\text { concentration of rosuvastatin }\end{array}$ & $\begin{array}{l}\text { Start with the lowest possible rosuvastatin dose, } \\
\text { monitor for signs and symptoms of toxicity }\end{array}$ \\
\hline Naproxen + Enoxaparin & 4 & $\mathrm{~F}$ & $\begin{array}{l}\text { NSAIDs }{ }^{c} \text { may enhance the anticoagulant } \\
\text { effect of enoxaparin }\end{array}$ & Monitor closely for signs and symptoms of bleeding \\
\hline Naproxen + Heparin & 4 & $\mathrm{~F}$ & $\begin{array}{l}\text { NSAIDs may enhance the anticoagulant } \\
\text { effect of heparin }\end{array}$ & Decrease the dose of heparin or NSAIDs \\
\hline Ibuprofen + Enoxaparin & 3 & $\mathrm{~F}$ & $\begin{array}{l}\text { NSAIDs may enhance the anticoagulant } \\
\text { effect of enoxaparin }\end{array}$ & Monitor closely for signs and symptoms of bleeding \\
\hline Indomethacin + Heparin & 3 & $\mathrm{~F}$ & $\begin{array}{l}\text { NSAIDs may enhance the anticoagulant } \\
\text { effect of heparin }\end{array}$ & Decrease the dose of heparin or NSAIDs \\
\hline Lopinavir/Ritonavir + Fentanyl & 3 & $\mathrm{~F}$ & $\begin{array}{l}\text { CYP3A4 inhibitors may increase the serum } \\
\text { concentration of fentanyl }\end{array}$ & $\begin{array}{l}\text { Monitor for increased adverse effects of fentanyl, } \\
\text { consider dose reduction }\end{array}$ \\
\hline Lopinavir/Ritonavir + Quetiapine & 3 & $\mathrm{~F}$ & $\begin{array}{l}\text { CYP3A4 inhibitors may increase the serum } \\
\text { concentration of quetiapine }\end{array}$ & $\begin{array}{l}\text { Consider using an alternative or reduce the quetia- } \\
\text { pine dose to one-sixth of the original dose }\end{array}$ \\
\hline $\begin{array}{l}\text { Carbamazepine + Lopinavir/ } \\
\text { Ritonavir }\end{array}$ & 2 & $\mathrm{~F}$ & $\begin{array}{l}\text { Carbamazepine may decrease the serum } \\
\text { concentration of lopinavir }\end{array}$ & $\begin{array}{l}\text { Use a twice-daily lopinavir/ritonavir regimen, } \\
\text { monitor for the reduced effect of lopinavir/ritonavir }\end{array}$ \\
\hline Clopidogrel + Heparin & 2 & $\mathrm{~F}$ & $\begin{array}{l}\text { Antiplatelet agents may enhance the anti- } \\
\text { coagulant effect of heparin }\end{array}$ & Decrease the dose of heparin or clopidogrel \\
\hline Indomethacin + Enoxaparin & 2 & $\mathrm{~F}$ & $\begin{array}{l}\text { NSAIDs may enhance the anticoagulant } \\
\text { effect of enoxaparin }\end{array}$ & Monitor closely for signs and symptoms of bleeding \\
\hline Midazolam + Fentanyl & 2 & $\mathrm{~F}$ & Increased CNS depressant effects & Close monitoring for adverse effects \\
\hline Propofol + Fentanyl & 2 & $\mathrm{~F}$ & Increase CNS depressant effects & Close monitoring for adverse effects \\
\hline $\begin{array}{l}\text { Lopinavir/ } \\
\text { Ritonavir + Chlordiazepoxide }\end{array}$ & 2 & $\mathrm{~F}$ & $\begin{array}{l}\text { CYP3A4 inhibitors may increase the serum } \\
\text { concentration of chlordiazepoxide }\end{array}$ & $\begin{array}{l}\text { Monitor for increased adverse effects of } \\
\text { chlordiazepoxide }\end{array}$ \\
\hline Lopinavir/Ritonavir + Digoxin & 2 & G & $\begin{array}{l}\text { Ritonavir may increase the serum concen- } \\
\text { tration of digoxin }\end{array}$ & $\begin{array}{l}\text { Reduce the digoxin dose ( } 30-50 \%) \text { or the dosing } \\
\text { frequency, monitor digoxin levels }\end{array}$ \\
\hline Lopinavir/Ritonavir + Oxycodone & 2 & $\mathrm{~F}$ & $\begin{array}{l}\text { CYP3A4 inhibitors may increase the serum } \\
\text { concentration of oxycodone }\end{array}$ & Monitor for increased adverse effects of oxycodone \\
\hline
\end{tabular}

${ }^{a}$ Reliability (Re) was scaled as excellent (E), good (G), and fair (F). ${ }^{b}$ Lopinavir/ritonavir is a strong inhibitor of CYP3A4. ${ }^{\mathrm{C}}$ Nonsteroidal antiinflammatory drugs. Unique drug pairs are shown in the Supplementary Material, Appendix 1.

inhibitor is used concomitantly [21]. However, differentiation between signs and symptoms of HMG-CoA reductase inhibitors toxicity and COVID-19 is challenging because myalgia and abnormal LFT can also be seen in patients with COVID-19 [9, 22]. Rosuvastatin also has the same interaction with protease inhibitors and its dose should not be exceeded than $10 \mathrm{mg} /$ day when coadministered with lopinavir/ritonavir [23]. Rhabdomyolysis is a serious consequence of this interaction, which was reported in patients who received lopinavir/ritonavir with atorvastatin or rosuvastatin [24, 25].

Anxiolytic/hypnotic/sedative agents such as alprazolam, chlordiazepoxide, and midazolam were administered in our patients. According to the Lexi-Interact database, evidence for the interaction of alprazolam or midazolam with lopinavir/ritonavir is rated as good and excellent; respectively, in terms of reliability. Other benzodiazepine agents that are less expected to interact with protease 
Table 3: Drug combinations, frequency, reliability rating, mechanism, and recommendations for $X$ interactions (avoid combination) based on Lexi-Interact database [11, 12].

\begin{tabular}{|c|c|c|c|c|}
\hline Drug combination & $\mathbf{n}$ & $\operatorname{Re}^{a}$ & Mechanism/effect & Recommendations \\
\hline $\begin{array}{l}\text { Lopinavir/Ritonavir + Fluticasone/ } \\
\text { Salmeterol }\end{array}$ & 7 & $\mathrm{~F}$ & $\begin{array}{l}\text { CYP3A4 inhibitors }{ }^{\mathrm{b}} \text { may increase the } \\
\text { serum concentration of salmeterol }\end{array}$ & $\begin{array}{l}\text { Avoid concomitant use or monitor for adverse effects of } \\
\text { salmeterol }\end{array}$ \\
\hline Lopinavir/Ritonavir + Tamsulosin & 4 & G & $\begin{array}{l}\text { CYP3A4 Inhibitors may increase the } \\
\text { serum concentration of tamsulosin }\end{array}$ & Avoid concomitant use \\
\hline $\begin{array}{l}\text { Ipratropium Bromide/ } \\
\text { Salbutamol + Promethazine }\end{array}$ & 2 & $\mathrm{~F}$ & Increase the anticholinergic effects & $\begin{array}{l}\text { Avoid concomitant use or monitor for anticholinergic } \\
\text { related toxicity }\end{array}$ \\
\hline Lopinavir/Ritonavir + Midazolam & 2 & $\mathrm{E}$ & $\begin{array}{l}\text { Protease Inhibitors may increase the } \\
\text { serum concentration of midazolam }\end{array}$ & $\begin{array}{l}\text { Avoid concomitant use or reduce doses of intravenous } \\
\text { midazolam particularly if multiple doses are used }\end{array}$ \\
\hline
\end{tabular}

${ }^{a}$ Reliability (Re) was scaled as excellent (E), good (G), and fair (F). ${ }^{b}$ Lopinavir/ritonavir is a strong inhibitor of CYP3A4. Unique drug pairs are shown in the Supplementary Material, Appendix 1.

Table 4: Logistic regression analysis for the risk factors of $D$ and $X$ interactions.

\begin{tabular}{|c|c|c|c|c|}
\hline \multirow[t]{2}{*}{ Variable } & \multicolumn{2}{|c|}{ Univariate analysis } & \multicolumn{2}{|c|}{ Multivariate analysis } \\
\hline & OR $(95 \% \mathrm{Cl})$ & p-Value & OR $(95 \% \mathrm{Cl})$ & p-Value \\
\hline \multicolumn{5}{|l|}{ Age, years } \\
\hline $\begin{array}{l}\geq 60 \\
<60\end{array}$ & $3.2(1.8-5.6)$ & $<0.01$ & $1.8(1.0-3.4)$ & 0.07 \\
\hline \multicolumn{5}{|l|}{ Sex } \\
\hline $\begin{array}{l}\text { Male } \\
\text { Female }\end{array}$ & $0.9(0.5-1.6)$ & 0.72 & - & - \\
\hline \multicolumn{5}{|l|}{ Comorbidity } \\
\hline Hypertension & $3.7(2.0-6.6)$ & $<0.01$ & $1.6(0.8-3.4)$ & 0.18 \\
\hline Obesity & $1.4(0.7-2.6)$ & 0.31 & - & - \\
\hline Diabetes & $2.6(1.4-4.9)$ & $<0.01$ & $1.5(0.7-3.2)$ & 0.26 \\
\hline $\mathrm{IHD}^{\mathrm{a}}$ & $7.4(3.0-18.1)$ & $<0.01$ & $4.6(1.7-12.7)$ & $<0.01$ \\
\hline $\mathrm{CRDs}^{\mathrm{b}}$ & $3.6(1.2-10.9)$ & 0.02 & $3.5(1.0-12.2)$ & 0.04 \\
\hline Neoplasms & $2.6(0.7-9.4)$ & 0.15 & - & - \\
\hline \multicolumn{5}{|l|}{ ICU admission } \\
\hline $\begin{array}{l}\text { Yes } \\
\text { No }\end{array}$ & $3.0(1.5-6.1)$ & $<0.01$ & $3.3(1.4-6.7)$ & $<0.01$ \\
\hline
\end{tabular}

Variables with univariate $p$-values of less than 0.05 were included in multivariate analysis. ${ }^{\mathrm{a}}$ Ischemic heart disease. ${ }^{\mathrm{b}} \mathrm{Chronic}$ respiratory diseases.

inhibitors (e.g. lorazepam, oxazepam, temazepam) can be administered instead of alprazolam [26]. Inhibition of CYP3A4, which is responsible for midazolam metabolism in the liver and intestines, elevates the serum concentration of midazolam. Severe prolonged sedation and increased length of hospital stay were reported among patients receiving a combination of a protease inhibitor and intravenous midazolam [27]. However, another study showed that clinical outcomes of HIV patients (on protease inhibitors regimen) who received intravenous midazolam for procedural sedation and those who received diazepam (that is less likely to interact with protease inhibitors) were similar [28]. Considering all the reports, this interaction is categorized as $\mathrm{X}$ in terms of risk rating and the combination should be administered with caution. A dose reduction of intravenous midazolam may be required [29].

SARS-CoV-2 may affect the cardiovascular system and lead to myocardial injury, acute heart failure, or worsening preexisting cardiovascular disease [30]. Therefore, the interaction of cardiovascular agents with investigational medications for COVID-19 should be mentioned. In the current study, nondihydropyridine calcium channel blockers (diltiazem), cardiac glycosides (digoxin), antiarrhythmic agents (amiodarone, lidocaine), and isosorbide dinitrate had D or X interactions with lopinavir/ritonavir. Metabolism inhibition of nondihydropyridine calcium channel blockers may elevate their serum concentration and the risk of $\mathrm{AV}$ nodal blockade. Monitoring the toxicity of calcium channel blockers and a 50\% dose reduction of diltiazem may be required [31]. The mechanism of $\mathrm{D}$ interaction between lopinavir/ritonavir and digoxin is probably due to inhibition of P-glycoprotein transporter and reduction of digoxin renal clearance by ritonavir [32]. Reducing digoxin dose (30-50\%) or dosing frequency as well as monitoring digoxin levels is recommended [33]. Lopinavir/ritonavir may enhance the serum concentration of amiodarone and subsequently its QTc-prolonging effect. This combination should be avoided when possible, if not, a dose reduction and serial ECG monitoring is recommended [34]. A combination of amiodarone and azithromycin should also be cautioned in COVID-19 patients due to the QTc prolongation synergism effect. Our previous study showed that DDIs are a risk factor for prolonging QTc in ICU admitted patients [35]. Nevertheless, the interaction between hydroxychloroquine and azithromycin, two medications with QTc prolongation effect coadministered in some COVID-19 patients, is graded as B interaction [36]. For $B$ interactions, no intervention is needed according to the Lexi-Interact database but calculating the risk score of 
QTc prolongation before administration of this combination to COVID-19 patients is a wisely measure.

Excessive inflammation, platelet activation, endothelial dysfunction, and stasis may lead to arterial and venous thrombotic disease in COVID-19 patients [37]. Drug interactions of common anticoagulants should be considered in these patients. In the current study, apixaban and rivaroxaban were administered to the patients. Among novel oral anticoagulants (NOACs), apixaban and rivaroxaban are substrates for both P-glycoprotein transporter and CYP3A4. Therefore, concomitant administration with inhibitors of CYP3A4 and P-glycoprotein transporter (e.g., lopinavir/ritonavir) should be avoided due to elevated serum concentration of apixaban and rivaroxaban and risk of bleeding [38].

Additionally, coadministration of antiplatelets or NSAIDs with anticoagulants may increase the risk of bleeding [39]. Because of underlying cardiovascular diseases in some COVID-19 patients, they may regularly use antiplatelet agents. NSAIDs may also be prescribed to relieve myalgia [40] or for their probable effect on SARS-CoV-2 (specifically indomethacin) [41]. Anticoagulants side effects should be monitored in COVID-19 patients receiving these combinations.

Administration of salmeterol or combination medications containing salmeterol may be indicated in COVID-19 patients with underlying chronic respiratory diseases. Lopinavir/ritonavir elevates serum concentration of salmeterol [42] and may predispose patients to cardiovascular adverse effects of beta2-agonists.

Another important interaction that may occur in COVID-19 male patients with older age is between tamsulosin and lopinavir/ritonavir. Although the adverse consequences of this interaction have not been evaluated in the clinical studies, this combination is contraindicated according to the tamsulosin drug label [43]. When the combination must be used, monitoring tamsulosin adverse effects (particularly orthostatic hypotension) is recommended.

Logistic regression analysis revealed that the occurrence of $\mathrm{D}$ and $\mathrm{X}$ pDDIs is significantly associated with two comorbidities (IHD and CRDs) and ICU admission. Patients with IHD or CRDs may receive the medications which interact with investigational drugs for COVID-19 especially protease inhibitors. We found other investigational medications (used for our patients) including hydroxychloroquine, ribavirin, remdesivir, favipiravir, interferon beta, or intravenous immunoglobulin do not have $\mathrm{D}$ or $\mathrm{X}$ interaction with commonly used medications for comorbidities. Therefore, these medicines are much safer than protease inhibitors in terms of DDIs. We also found that critically ill patients are more prone to DDIs because they have complicated conditions and receive more medications.

Our study has some limitations. First, we could not find the evidence for the occurrence of side effects related to pDDIs in the patients' records. However, this may be related to the critical pandemic condition and time limitation for recording subjective and objective evidence for an actual DDI. This evidence can be collected through a prospective study in order to report actual DDIs. In addition, as a cross-sectional (descriptive-analytical) study, we found the potential risk factors of DDIs in COVID-19 patient. However, due to the limitation of this kind of studies, it should be cared not to make causal inferences [44]. Second, the software utilized by health-care practitioners to find DDIs cannot analyze individual genetic variation, which has an important effect on the occurrence and severity of DDIs [45]. The Lexi-Interact database also has this limitation. Third, some hospitals or countries may manage the patients differently. However, according to a systematic review, treatment protocols between countries vary slightly [46]. Therefore, our results can be extrapolated to the settings with similar prescribed medications.

\section{Conclusions}

Patients with COVID-19 exposed to many pDDIs that $18 \%$ of them were clinically important with the good and excellent levels of evidence. The interactions are more likely to happen in COVID-19 patients receiving medications with the potential of DDIs (protease inhibitors) and having comorbidity (IHD and CRDs). Choosing an alternative medication or adjusting the dosage of interacting drugs can improve patients' management by both providing essential medications and preventing adverse drug effects.

Acknowledgments: We thank all health care workers of Masih Daneshvari hospital working at the front line against COVID-19. We also appreciate information technology and health records staff of the hospital for providing electronic health records.

Research funding: This study was funded by the National Research Institute of Tuberculosis and Lung Diseases.

Author contributions: All authors have accepted responsibility for the entire content of this manuscript and approved its submission.

Competing interests: Authors state no conflict of interest. 
Informed consent: Written informed consent by the patients was waived due to the retrospective nature of the investigation.

Ethical approval: The Ethical Review Board of the national research institute of tuberculosis and lung diseases approved the study protocol.

\section{References}

1. World Health Organization. Coronavirus disease 2019 (COVID-19) situation report - 51; 2020. Available from: https://www.who. int/docs/default-source/coronaviruse/situation-reports/ 20200311-sitrep-51-covid-19.pdf [Accessed 11 Dec 2020].

2. Yang W, Cao Q, Qin L, Wang X, Cheng Z, Pan A, et al. Clinical characteristics and imaging manifestations of the 2019 novel coronavirus disease (COVID-19): A multi-center study in Wenzhou city, Zhejiang, China. J Infect 2020;80:388-93.

3. Centers for Disease Control and Prevention. People at Increased Risk. U.S. Department of Health \& Human Services; 2020. Available from: https://www.cdc.gov/coronavirus/2019-ncov/ need-extra-precautions/index.html [Accessed 11 Dec 2020].

4. Frequently Asked Questions. U.S. Food and Drug Administration; 2020. Available from: https://www.fda.gov/emergencypreparedness-and-response/coronavirus-disease-2019-covid19/coronavirus-disease-2019-covid-19-frequently-askedquestions [Accessed 20 Jul 2020].

5. Becker RC. Covid-19 treatment update: follow the scientific evidence. J Thromb Thrombolysis 2020;50:43-53.

6. Afsaneh $\mathrm{G}$. The hunt for an effective treatment for COVID-19| Feature. Pharm J 2020. Available from: https://www. pharmaceutical-journal.com/news-and-analysis/features/thehunt-for-an-effective-treatment-for-covid-19/20207883.article? firstPass=false [Accessed $17 \mathrm{Jul}$ 2020].

7. Assessment of evidence for COVID-19-related treatments. Updated 12/02/2020. Available from: https://www.ashp.org/-/ media/assets/pharmacy-practice/resource centers/ Coronavirus/docs/ASHP-COVID-19-Evidence-Table.ashx? [Accessed 11 Dec 2020].

8. Preskorn SH, Quadri S. Why are patients with COVID-19 at risk for drug-drug interactions? Psychiatric Times 2020. Available from: https://www.psychiatrictimes.com/view/why-patients-withcovid19-risk-drug-drug-interactions [Accessed 11 Dec 2020].

9. Back D, Marzolini C, Hodge C, Marra F, Boyle A, Gibbons S, et al. COVID-19 treatment in patients with comorbidities: awareness of drug-drug interaction. Br J Clin Pharmacol 2020. https://doi.org/ 10.1111/bcp.14358 [Epub ahead of print].

10. Lemaitre F, Solas C, Grégoire M, Lagarce L, Elens L, Polard E, et al. Potential drug-drug interactions associated with drugs currently proposed for COVID-19 treatment in patients receiving other treatments. Fundam Clin Pharmacol 2020. In Press.

11. Lexi-interact data fields. Available from: http://webstore.lexi. com/Information/Product-Information/Lexi-Interact-Fields [Accessed 11 Dec 2020].

12. Lexicomp® online product description. Available from: http:// www.eisi.com.ph/docs/lexi/Lexicomp\%200nline\%20Product\% 20Description.pdf [Accessed 11 Dec 2020].

13. Micromedex ${ }^{\circledR}$ user guide. Available from: http://www. micromedexsolutions.com/micromedex2/4.107.0/webtier/
pdf/UserGuide.pdf?navitem=linksUserGuide [Accessed 11 Dec 2020].

14. Croxtall JD, Perry CM. LopinavirRitonavir: A review of its use in the management of HIV-1 infection. Drugs 2010;70:1885-915.

15. Chu CM, Cheng VCC, Hung IFN, Wong MM, Chan KH, Chan KS, et al. Role of lopinavir/ritonavir in the treatment of SARS: initial virological and clinical findings. Thorax 2004;59:252-56.

16. Chan JFW, Yao Y, Yeung ML, Deng W, Bao L, Jia L, et al. Treatment with lopinavir/ritonavir or interferon- $\beta 1 \mathrm{~b}$ improves outcome of MERSCoV infection in a nonhuman primate model of common marmoset. J Infect Dis 2015;212:1904-913.

17. Hung IF, Lung K, Tso EY, Liu R, Chung TW, Chu MY, et al. Articles Triple combination of interferon beta-1b, lopinavir - ritonavir, and ribavirin in the treatment of patients admitted to hospital with COVID-19: an open-label, randomised, phase 2 trial. Lancet 2020;6736:1-10.

18. Chandwani A, Shuter J. Lopinavir/ritonavir in the treatment of HIV-1 infection: a review. Therapeut Clin Risk Manag 2008;4: 1023-33.

19. Hsyu PH, Schultz-Smith MD, Lillibridge JH, Lewis RH, Kerr BM. Pharmacokinetic interactions between nelfinavir and 3-hydroxy3-methylglutaryl coenzyme A reductase inhibitors atorvastatin and simvastatin. Antimicrob Agents Chemother 2001;45: 3445-50.

20. Pham PA, la Porte CJ, Lee LS, Van Heeswijk R, Sabo JP, Elgadi MM, et al. Differential effects of tipranavir plus ritonavir on atorvastatin or rosuvastatin pharmacokinetics in healthy volunteers. Antimicrob Agents Chemother 2009;53:4385-92.

21. Lopinavir and Ritonavir - Atorvastatin. Lexicomp drug interactions. Hudson, Ohio: Wolters Kluwer Clinical Drug Information, Inc.; 2020. Available from: http://online.lexi.com.

22. Zhang C, Shi L, Wang FS. Liver injury in COVID-19: management and challenges. Lancet Gastroenterol Hepatol 2020;5:428-30.

23. Lopinavir and Ritonavir - Rosuvastatin. Lexicomp drug interactions. Hudson, Ohio: Wolters Kluwer Clinical Drug Information, Inc.; 2020. Available from: http://online.lexi.com.

24. Mah Ming JB, Gill MJ. Drug-induced rhabdomyolysis after concomitant use of clarithromycin, atorvastatin, and lopinavir/ ritonavir in a patient with HIV. AIDS Patient Care STDS 2003;17: 207-10.

25. De Kanter CT, Keuter M, Van Der Lee MJ, Koopmans PP, Burger DM. Rhabdomyolysis in an HIV-infected patient with impaired renal function concomitantly treated with rosuvastatin and lopinavir/ritonavir. Antivir Ther 2011;16:435-7.

26. Lopinavir and Ritonavir - Alprazolam. Lexicomp drug interactions. Hudson, Ohio: Wolters Kluwer Clinical Drug Information, Inc.; 2020. Available from: http://online.lexi.com.

27. Jenh Hsu A, Carson KA, Yung R, Paul A. Severe prolonged sedation associated with coadministration of protease inhibitors and intravenous midazolam during bronchoscopy. Pharmacotherapy 2012;32:538-45.

28. Backman ES, Triant VA, Ehrenfeld JM, Lu Z, Arpino P, Losina E, et al. Safety of midazolam for sedation of HIV-positive patients undergoing colonoscopy. HIV Med 2013;14:379-84.

29. Lopinavir and Ritonavir - Midazolam. Lexicomp drug interactions. Hudson, Ohio: Wolters Kluwer Clinical Drug Information, Inc.; 2020. Available from: http://online.lexi.com.

30. Clerkin KJ, Fried JA, Raikhelkar J, et al. COVID-19 and cardiovascular disease. Circulation 2020;141:1648-55. 
31. Lopinavir and Ritonavir - Diltiazem. Lexicomp drug interactions. Hudson, Ohio: Wolters Kluwer Clinical Drug Information, Inc.; 2020. Available from: http://online.lexi.com.

32. Kirby BJ, Collier AC, Kharasch ED, Whittington D, Thummel KE, Unadkat JD. Complex drug interactions of the HIV protease inhibitors 3: effect of simultaneous or staggered dosing of digoxin and ritonavir, nelfinavir, rifampin, or bupropion. Drug Metab Dispos 2012;40:610-6.

33. Lopinavir and Ritonavir - Digoxin. Lexicomp drug interactions. Hudson, Ohio: Wolters Kluwer Clinical Drug Information, Inc.; 2020. Available from: http://online.lexi.com.

34. Lopinavir and Ritonavir - Amiodarone. Lexicomp drug interactions. Hudson, Ohio: Wolters Kluwer Clinical Drug Information, Inc.; 2020. Available from: http://online.lexi.com.

35. Hosseinpoor Z, Farzanegan B, Seyyedi SR, Rajabi M, Baniasadi S. Drug interactions and creatinine levels are associated with QTC prolongation in intensive care units: a prospective, observational study. Drug Metab Pers Ther 2019;34:2-8.

36. Hydroxychloroquine - Azithromycin. Lexicomp drug interactions. Hudson, Ohio: Wolters Kluwer Clinical Drug Information, Inc.; 2020. Available from: http://online.lexi.com.

37. Bikdeli B, Madhavan MV, Jimenez D, Chuich T, Dreyfus I, Driggin E, et al. COVID-19 and thrombotic or thromboembolic disease: implications for prevention, antithrombotic therapy, and followup: JACC state-of-the-art review. J Am Coll Cardiol 2020;75: 2950-73.

38. Vranckx $P$, Valgimigli $M$, Heidbuchel $H$. The significance of drugdrug and drug-food interactions of oral anticoagulation. Arrhythmia Electrophysiol Rev 2018;7:55-61.
39. Delaney JA, Opatrny L, Brophy JM, Suissa S. Drug-drug interactions between antithrombotic medications and the risk of gastrointestinal bleeding. CMAJ (Can Med Assoc J) 2007;177: 347-51.

40. Coronavirus disease 2019 (COVID-19) - Diagnosis and treatment Mayo clinic. Available from: https://www.mayoclinic.org/ diseases-conditions/coronavirus/diagnosis-treatment/drc20479976 [Accessed 20 Jul 2020].

41. Amici C, Di Caro A, Ciucci A, et al. Indomethacin has a potent antiviral activity against SARS coronavirus. Antivir Ther 2006;11: 1021-30.

42. Lopinavir and Ritonavir - Salmeterol. Lexicomp drug interactions. Hudson, Ohio: Wolters Kluwer Clinical Drug Information, Inc.; 2020. Available from: http://online.lexi.com.

43. Flomax (tamsulosin) [prescribing information]. Available from: https://www.accessdata.fda.gov/drugsatfda_docs/label/2009/ 020579s026lbl.pdf [Accessed 11 Dec 2020].

44. Kesmodel US. Cross-sectional studies - what are they good for? Acta Obstet Gynecol Scand 2018;97:388-93.

45. Malki MA, Pearson ER. Drug-drug-gene interactions and adverse drug reactions. Pharmacogenomics J 2020;20:355-66.

46. Tobaiqy M, Qashqary M, Al-Dahery S, Mujallad A, Hershan AA, Kamal MA, et al. Therapeutic management of patients with COVID-19: a systematic review. Infection Prevention in Practice 2020;2:100061.

Supplementary Material: The online version of this article offers supplementary material (https://doi.org/10.1515/dmdi-2020-0145). 